\title{
IDENTIFIKASI INTRUSI AIR LAUT PADA AIR TANAH MENGGUNAKAN METODE INDUCED POLARIZATION STUDI KASUS DAERAH SURABAYA TIMUR
}

\author{
Bagas Aryaseta, Dwa Desa Warnana, Amien Widodo \\ Jurusan Teknik Geofisika, FTSP Instittut Teknologi Sepuluh Nopember \\ e-mail: aryaseta.bagas@gmail.com
}

\begin{abstract}
Abstrak. Sebagian besar air tanah di wilayah kota Surabaya sudah mengalami intrusi air laut dan memiliki kadar garam yang tidak sesuai standar air minum. Permasalahan akifer air tanah yang sudah terintrusi air laut diidentifikasi menggunakan metode Induced Polarization dilengkapi dengan data sumur dan data resistivity sebagai data pelengkap. Pengukuran data sumur dilakukan di beberapa lima belas titik di Surabaya Timur yang hasilnya menunjukkan parameter-parameter air seperti salinitas, TDS, konduktivitas, dan pH. Pengukuran Induced Polarization dan Resistivity metode Wener-Schlumberger dilakukan di tiga lintasan di Surabaya Timur yang tersebar di daerah air asin, air payau rendah, dan air tawar. Penampang Chargeability dan Resistivity memiliki penetrasi kedalaman $9 \mathrm{~m}$ menunjukkan hasil yang cukup baik dalam mengidentifikasi akifer air tanah. Akifer dengan nilai resistivitas rendah (6.81 ohm.m) dan chargeabilitas rendah (<0.302 msec) besar kemungkinan merupakan air asin.
\end{abstract}

Kata Kunci: intrusi air laut; akifer; Surabaya Timur; IP; resistivity

\begin{abstract}
Most of the groundwater in city of Surabaya has undergone sea water intrusion and its salinity are not suitable for drinking water standards. Groundwater aquifer problem that has been intruded seawater identified using the IP method with wells data and data resistivity as correlation data. Measurement of wells data is carried out in fifteen points in east Surabaya that the results indicate the water parameters such as salinity, TDS, conductivity, and $\mathrm{pH}$. Measurement of Induced Polarization and Resistivity with Wenner-Schlumberger methods conducted at three lines in east Surabaya, spread across saltwater, fresh to brackish water, and fresh water. Cross section of chargeability and resistivity has a penetration depth of $9 \mathrm{~m}$ showed good results in identifying the groundwater aquifer. Aquifer with low resistivity values (6.81 ohm.m) and low chargeability values (<0.302 msec) likely is saltwater.
\end{abstract}

Keywords: seawater intrusion; aquifer; east Surabaya; IP; resistivity

\section{PENDAHULUAN}

Daerah Surabaya merupakan daerah perkotaan dengan populasi penduduk sebanyak 2,765 juta jiwa (UN data, 2010). Sebagian wilayah Surabaya Timur tepatnya Gunung Anyar hingga Kenjeran merupakan daerah pesisir. Kawasan Pesisir Surabaya merupakan Kawasan Strategis Ekonomi dengan luas wilayah 521,62 hektare yang terdiri dari dua kecamatan (Kenjeran dan Bulak) dan enam kelurahan dengan panjang garis Pantai 8627.80 meter (Hakim, 2015). Sehingga tidak dipungkiri sebagian air sumur di wilayah Surabaya memiliki rasa asin karena salinitas tinggi yang disebabkan adanya asosiasi dengan wilayah pantai.

Penelitian ini dilakukan untuk mengidentifikasi adanya zona intrusi air laut pada air tanah dengan metode IP 2D. Sebagai acuan untuk membuat desain akuisisi digunakan data parameter air tanah yang diambil dari sumur di beberapa titik di Surabaya Timur. Parameter air tanah yang diukur antara lain $\mathrm{pH}$, konduktivitas, TDS, salinitas, dan kedalaman akifer sumur. Dari penelitian ini diharapkan adanya hubungan yang terlihat jelas antara metode IP 2D dengan parameter air terutama konduktivitas dan salinitas yang disebabkan adanya intrusi air laut. Metode Induced Polarization 2D akan menghasilkan penampang chargeabilitas bawah permukaan. Penampang tersebut akan dianalisa untuk melihat perbedaan chargeabilitas pada akifer air tawar dan air asin. 


\section{TINJAUAN PUSTAKA}

\section{Hidrogeologi Surabaya}

Surabaya merupakan ibukota Provinsi Jawa Timur dan kota terbesar kedua di Indonesia. Kota Surabaya terletak pada $7^{\circ} 9^{\prime}-7^{\circ} 21^{\prime}$ LS dan $112^{\circ} 36^{\prime}$ $112^{\circ} 57^{\prime}$ BT. Luas daratan sebesar 33.048 Hektar dan luas wilayah laut yang telah dikelola pemerintah kota sebesar 19.039 Hektar. Topografi Kota Surabaya adalah $80 \%$ merupakan dataran rendah dengan ketinggian 3-6 meter di atas permukaan air laut. Dataran rendah Kota Surabaya terbentuk dari endapan alluvial sungai dan endapan pantai. Sedangkan 20\% Kota Surabaya merupakan daerah perbukitan landai dengan ketinggian 25-50 meter diatas permuakaan air laut yang berupa tanah dengan kadar kapur yang tinggi. (BAPPEDA, 2013).

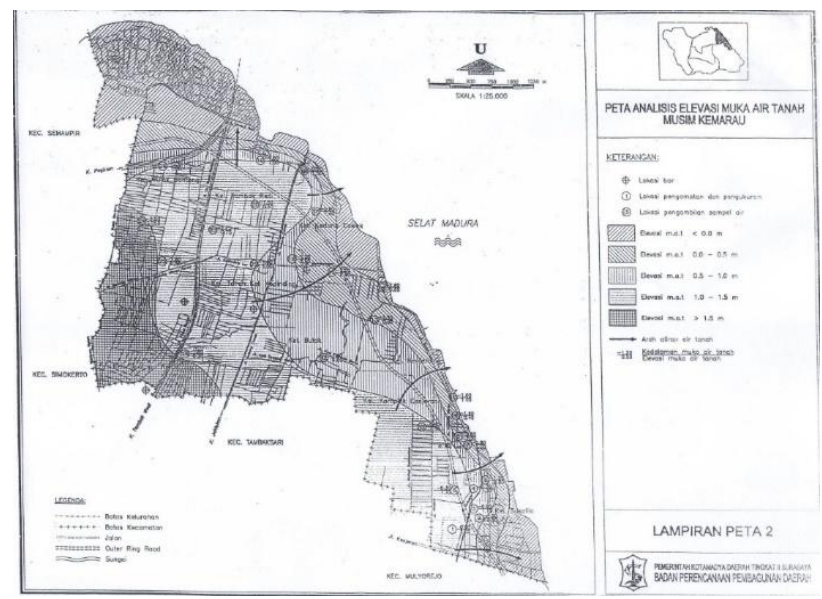

Gambar 1. Peta Elevasi Muka Air Tanah Musim Kemarau Kota Surabaya (ITS \& BAPEDDA, 1999).

\section{Intrusi Air Laut}

Intrusi air laut adalah penyusupan air laut (air asin) ke dalam akuifer air tawar. Intrusi air laut sering terjadi di daerah yang berdekatan dengan pesisir. Hal ini terjadi karena terganggunya keseimbangan hidrostatik antara air bawah tanah tawar dan air bawah tanah asin. Terdapat beberapa faktor terjadinya intrusi air laut antara lain :

1. Penurunan muka air bawah tanah atau bidang piso metrik di daerah pantai.

2. Pemompaan air bawah tanah daerah pantai yang berlebihan.

3. Masuknya air laut ke daratan melalui sungai, kanal, saluran, rawa, dan cekungan lainnya.
Umumnya intrusi air laut terjadi di daerah perkotaan, ini disebabkan oleh terlalu banyaknya manusia mengambil air bawah tanah tanpa adanya feedback yang setimpal untuk regenerasi air tanah itu sendiri. Intrusi air laut mengakibatkan berkurangnya mutu air bawah tanah. Air tanah yang sebelumnya layak untuk digunakan sebagai air minum menjadi tidak layak lagi untuk digunakan. (Hendrayana, 2002).

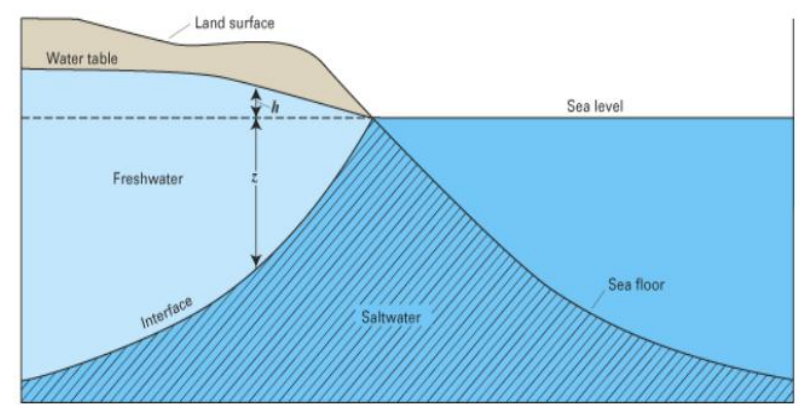

Gambar 2. Ilustrasi Hubungan Antara Air Tawar dengan Air Asin di Daerah Pesisir (Ambarsari, 2013).

\section{Metode IP (Induced Polarization)}

Prinsip metode IP adalah mengalirkan arus listrik ke dalam bumi dan mengamati beda potensial yang terjadi setelah arus listrik dihentikan. Pada saat arus diinjeksikan, ion-ion dalam pori-pori batuan akan teridistribusi dari posisi stabil menjadi tidak stabil. Ketika arus diputus, seharusnya beda potensial langsung menjadi nol, akan tetapi pada medium-medium tertentu beda potensial tidak langung menjadi nol dikarenakan medium bersifat seperti kapasitor (menyimpan senergi listrik). Energi listrik masih tersimpan dalam bentuk energi elektrokimia pada fluida elektrolit maupun mineral konduktif pada pori-pori batuan. Jadi setelah arus diputus, ion-ion yang sebelumnya mengalami pengkutuban berangsur-angsur kembali ke keadaan seimbangnya dengan kata lain masih terdapat beda tegangan yang akan meluruh terhadap waktu sampai nilainya menjadi nol. (Telford, 1990).

Pengukuran IP dalam time domain dilakukan dengan cara menginjeksikan arus listrik dan 
kemudian mengukur beda potensial setelah arus dimatikan. Pengukuran nilai beda potensial dilakukan hingga tegangan mencapai nilai nol. Parameter yang diukur adalah tegangan primer (Vp) yaitu tegangan ketika arus belum dimatikan dan tegangan sekunder (Vs) yaitu tegangan yang terukur selama waktu peluruhan. Untuk mengetahui besar nilai perbandingan efek polarisasi maka dibandingkan nilai Vp dan Vs dalam selang waktu t1 kemudian dikalikan $100 \%$.

$$
\text { IPEffect }=\frac{V s(t 1)}{V p} \times 100 \%
$$

Untuk menghitung nilai apparent chargeability (Ma) dilakukan dengan cara membandingkan nlai Vp dengan nilai rata-rata Vs yang diperoleh dengan cara mengintegralkan Vs terhadap sampel waktu peluruhan.

$$
M a=\frac{1}{V} \int_{t 1}^{t 2} V(t) d t
$$

Apparent chargeability menunjukkan lama tidaknya efek polarisasi sesaat setelah arus dimatikan. Apabila waktu delay lama maka nilai Ma besar sehingga dapat diamsusikan adanya mineral konduktif. (Sharma, 1997)

\section{Metode Wenner-Schlumberger}

Konfigurasi Wenner-Schlumberger adalah konfigurasi dengan sistem aturan spasi yang konstan dengan catatan faktor pembanding " $\mathrm{n}$ " untuk konfigurasi ini adalah perbandingan jarak antara elektroda arus (AB) dengan potensial (MN). Apabila jarak elektroda potensial $\mathrm{MN}$ adalah a maka jarak elektroda $A B$ adalah 2 na+a.

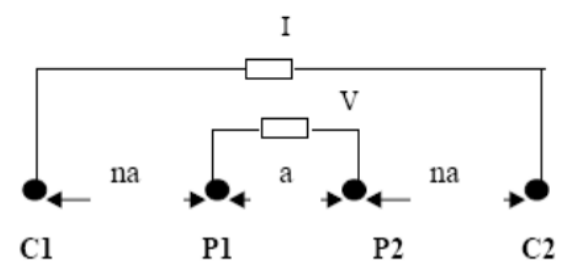

Gambar 3. Konfigurasi Wenner-Schlumberger. (Priambodo, Purnomo, Rukmana, \& Juanda, 2011)

\section{METODOLOGI PENELITIAN}

Pengambilan sampel air sumur dilaksanakan pada tanggal 10 November 2016. Lokasi pengambilan sampel air sumur dapat dilihat pada titik-titik warna kuning pada gambar di bawah ini.

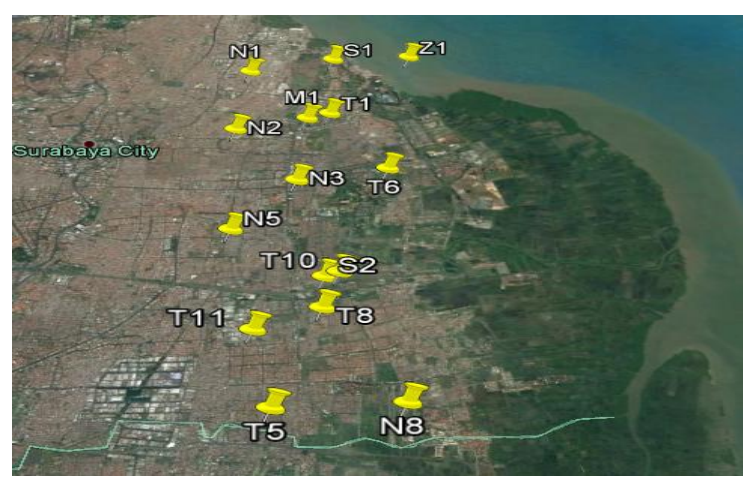

Gambar 4. Titik Pengambilan Sampel Air Sumur.

Desain akuisisi metode IP menggunakan acuan data sampel sumur yang telah diuji salinitasnya. Terdapat 3 lokasi pengukuran dengan desain line pengukuran ditunjukkan oleh titik merah pada gambar di bawah ini.

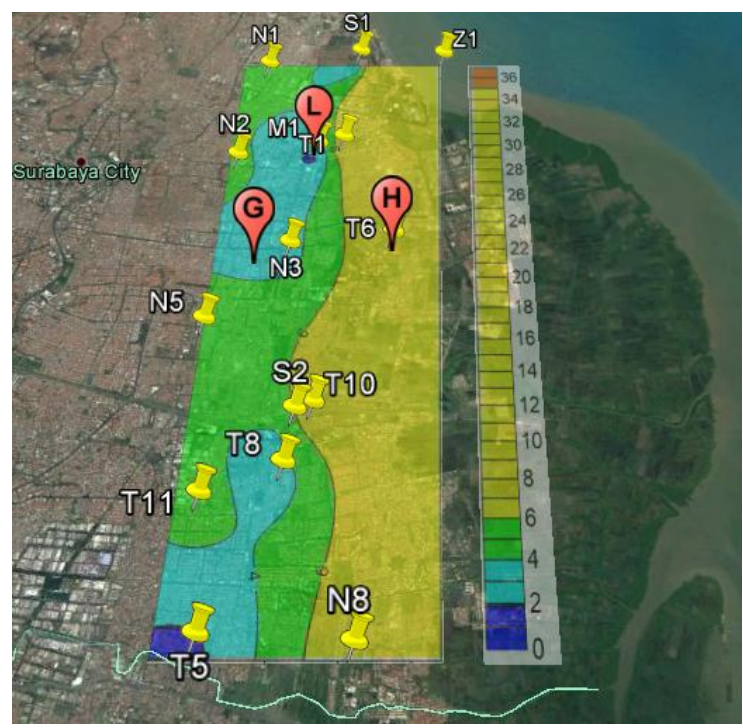

Gambar 5. Desain Akuisisi. 

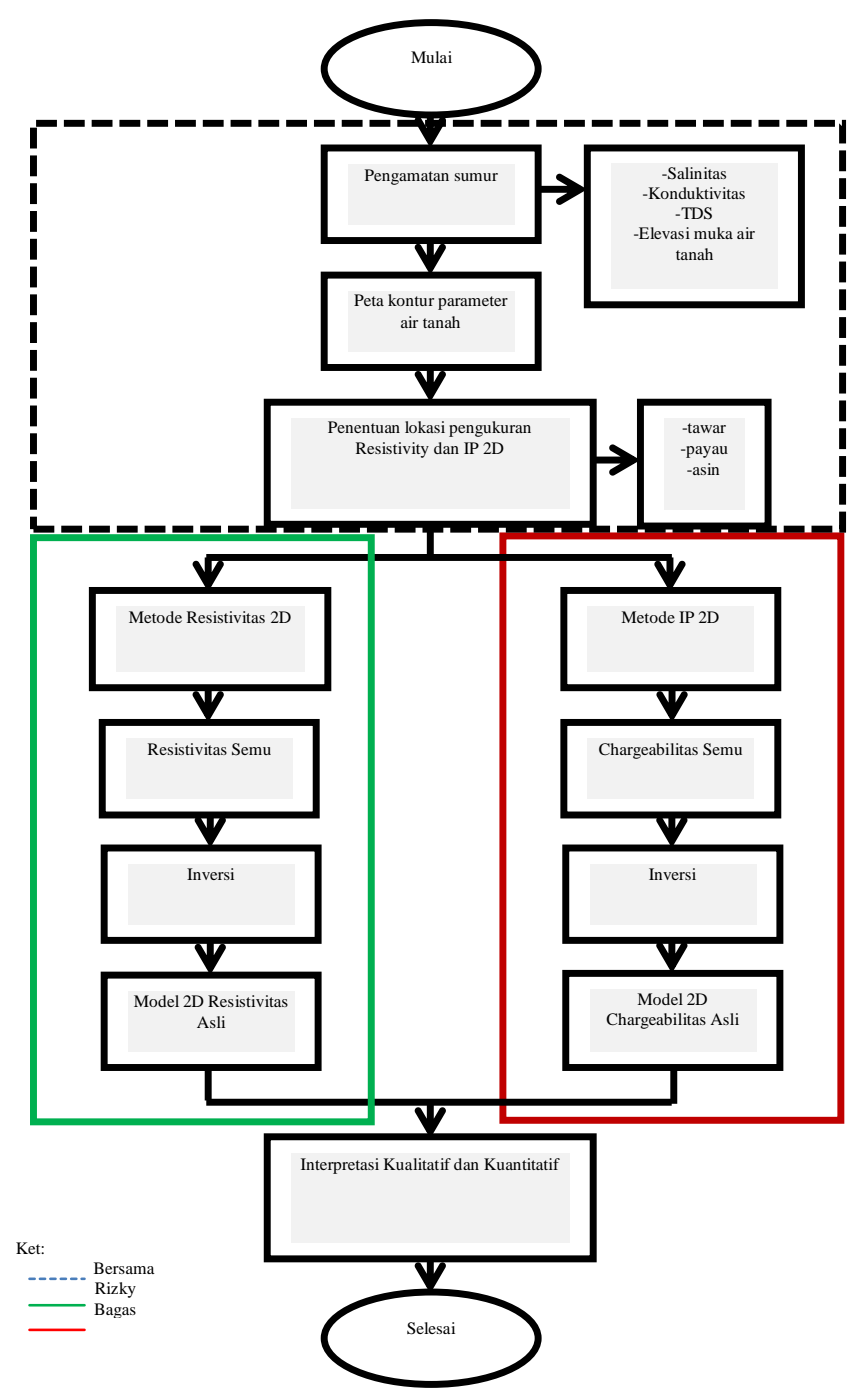

Gambar 6. Diagram Alir Penelitian.

\section{HASIL DAN PEMBAHASAN}

\section{Analisis Data Sumur}

Data sumur didapatkan dari pengambilan sampel air sumur di beberapa wilayah di Surabaya Timur pada tanggal 10 November 2016 (musim penghujan). Pengambilan air sumur dilakukan dengan menggunakan alat water sampler dengan tujuan untuk mengambil air sumur yang berada di dasar sumur, sehingga diperoleh hasil berupa air yang asli berasal dari sumur tersebut. Kemudian sampel air sumur dimasukkan ke dalam botol. Dari sampel air tersebut dilakukan analisa sifat atau parameter air dengan menggunakan alat water quality tester WT61 untuk mengetahui kualitas dan jenis air tanahnya. Parameter yang diukur antara lain salinitas, konduktivitas, tds, dan pH. Selain pengambilan sampel, juga dilakukan pengeplotan titik sumur menggunakan GPS untuk mendapatkan koordinat dan elevasi daerah setempat. Elevasi muka air tanah didapatkan dengan mengurangi elevasi setempat dengan kedalaman muka air tanah. Hasil pengukuran kualitas sampel air sumur dapat dilihat pada Tabel 1 di bawah ini.

Tabel 1. Kualitas Sampel Air Sumur.

\begin{tabular}{|c|c|c|c|c|c|c|c|c|c|}
\hline sumur & \multicolumn{2}{|c|}{ koordinat } & $\begin{array}{c}\text { elevasi } \\
\text { setempat } \\
(\mathrm{cm})\end{array}$ & $\begin{array}{c}\text { muka air } \\
\text { tanah (cm) }\end{array}$ & $\begin{array}{c}\text { elevasi } \\
\text { muka air } \\
\text { tanah } \\
(\mathrm{cm})\end{array}$ & ph & $\begin{array}{c}\text { kondukti } \\
\text { vitas } \\
(\mathrm{mS})\end{array}$ & tds (ppt) & $\begin{array}{c}\text { salinitas } \\
\text { (ppt) }\end{array}$ \\
\hline S1 & 697734 & 9199361 & 200 & 82 & 118 & 6.56 & 5.67 & 3.78 & 2.83 \\
\hline S2 & 697028 & 9191564 & 400 & 79 & 321 & 6.37 & 8.6 & 5.73 & 4.3 \\
\hline T1 & 697505 & 9197069 & 100 & 74 & 26 & 6.64 & 14.34 & 9.49 & 7.12 \\
\hline T5 & 695964 & 9188312 & 500 & 89 & 411 & 6.56 & 2.86 & 1.9 & 1.43 \\
\hline T8 & 696928 & 9190704 & 500 & 74 & 426 & 6.59 & 5.87 & 3.92 & 2.94 \\
\hline T10 & 697298 & 9191672 & 400 & 91 & 309 & 6.41 & 14.95 & 9.92 & 7.45 \\
\hline T11 & 695736 & 9190245 & 500 & 10 & 490 & 6.48 & 10.39 & 6.92 & 5.18 \\
\hline T6 & 698486 & 9194877 & 300 & 49 & 251 & 6.28 & 17.06 & 11.35 & 8.52 \\
\hline M1 & 697028 & 9196930 & 100 & 69 & 31 & 6.62 & 3.27 & 2.18 & 1.63 \\
\hline N1 & 695908 & 9199011 & 400 & 47 & 353 & 6.51 & 11.93 & 7.95 & 5.96 \\
\hline N2 & 695552 & 9196647 & 200 & 79 & 121 & 6.58 & 9.9 & 6.6 & 4.96 \\
\hline N3 & 696694 & 9194657 & 500 & 74 & 426 & 6.68 & 1.71 & 2.28 & 3.42 \\
\hline N5 & 695408 & 9193154 & 500 & 28 & 472 & 6.25 & 10.49 & 6.98 & 5.25 \\
\hline N8 & 698105 & 9188210 & 300 & 87 & 213 & 6.43 & 15.64 & 10.41 & 7.82 \\
\hline Z1 & 699406 & 9199294 & 0 & 0 & 0 & 7.83 & 55 & 35 & 35 \\
\hline
\end{tabular}

Parameter data yang diukur untuk mengetahui elevasi muka air tanah adalah koordinat sumur, data elevasi setempat (muka tanah), dan data kedalaman muka air tanah. Elevasi muka air tanah didapatkan dari pengurangan data elevasi setempat dengan kedalaman muka air tanah. Penggambaran kontur peta muka air tanah menggunakan software Surfer dengan memasukkan data koordinat dan elevasi muka air tanah tiap sumur. Garis kontur menunjukkan daerah-daerah yang memiliki tinggi muka air tanah yang sama yang dibuat melalui interpolasi data titik-titik sumur yang telah diketahui. Dari peta kontur muka air tanah dapat ditentukan garis-garis arah aliran (flow line) air tanah dengan menarik garis tegak lurus kontur muka air tanah. Garis arah aliran air tanah berfungsi untuk memprediksi arah pencemaran air tanah, mengetahui daerah tangkapan (recharge), dan daerah pemanfaatan (discharge). Dari Gambar 7 dapat dilihat bahwa semakin curam kontur muka air tanah akan semakin besar vektor aliran air tanahnya. Sebagai contoh dapat dilihat pada titik N3 sampai titik M1, vektor arah dan besar aliran air tanah sangat besar dikarenakan kontur yang curam. 


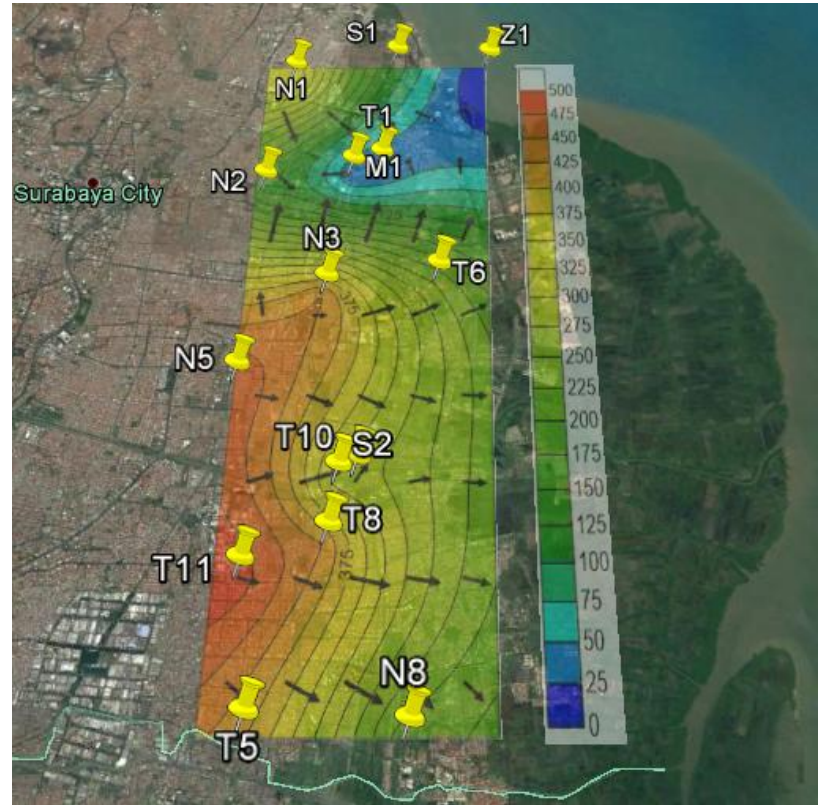

Gambar 7. Arah Aliran Ar Tanah.

Selain pembuatan arah aliran air tanah, dari elevasi muka air tanah juga dapat digunakan untuk membuat penampang Ghyben-Herzberg. Dari penampang Ghyben-Herzberg dapat diperlihatkan letak air laut di bawah permukaan tanah. Letak air laut adalah sebesar 40 kali tinggi elevasi muka air tanah. Dari penampang air tanah dilakukan slicing (garis warna merah) seperti pada Gambar $8 \mathrm{di}$ bawah. Cross-section hasil slicing dapat dilihat pada Gambar 9.

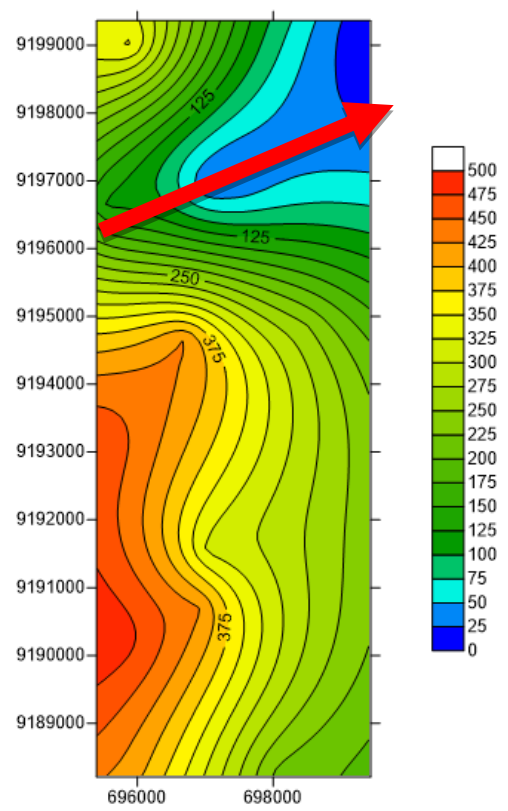

Gambar 8. Slicing Kontur Muka Air Tanah.

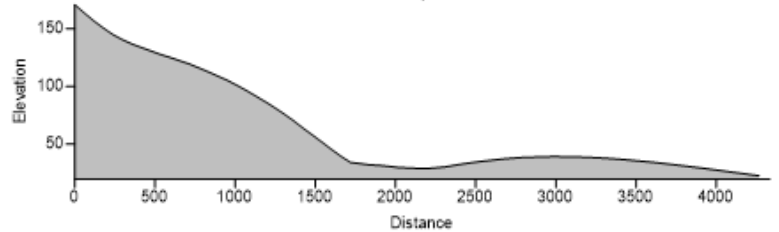

Gambar 9. Cross-Section Hasil Slicing Muka Air Tanah.

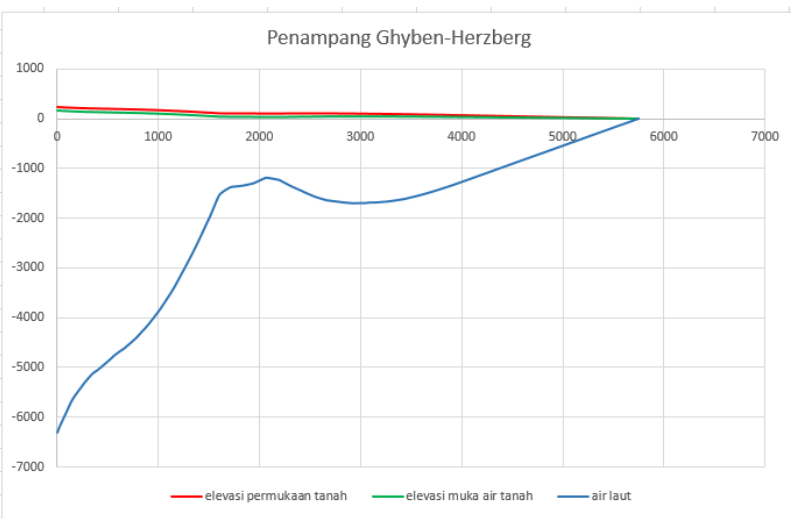

Gambar 10. Penampang Ghyben-Herzberg Hasil Slicing.

Pada penampang hasil slicing terlihat bahwa terdapat kenaikan air laut. Hal ini disebabkan oleh penurunan muka air tanah. Menurunnya muka air tanah dapat disebabkan oleh pengambilan air yang berlebihan pada daerah tersebut.

Data parameter kualitas air diperoleh dari pengambilan beberapa sampel air sumur untuk selanjutnya diuji kualitasnya menggunakan Water Tester WT61. Data parameter air sumur yang ditunjukkan pada Tabel 1 diatas meliputi salinitas, TDS, konduktivitas, dan $\mathrm{pH}$. Untuk mempermudah melakukan analisa, hasil dari uji kualitas air selanjutnya dibuat menjadi kontur-kontur.

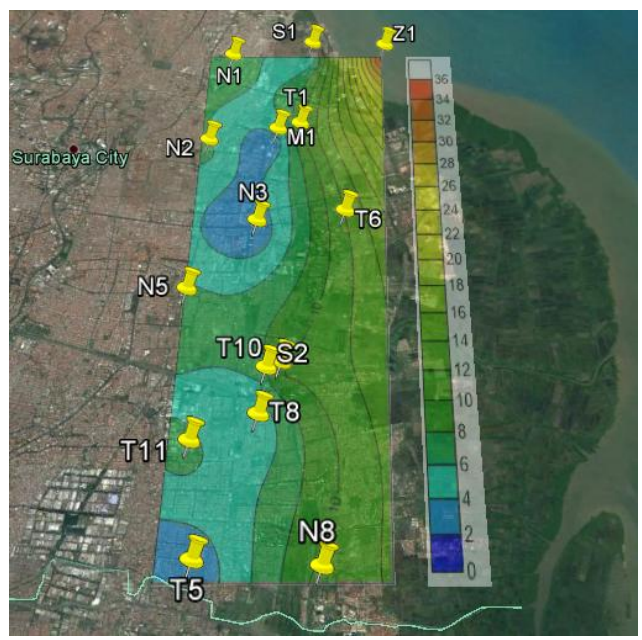

Gambar 11. Kontur Salinitas (dalam ppt). 


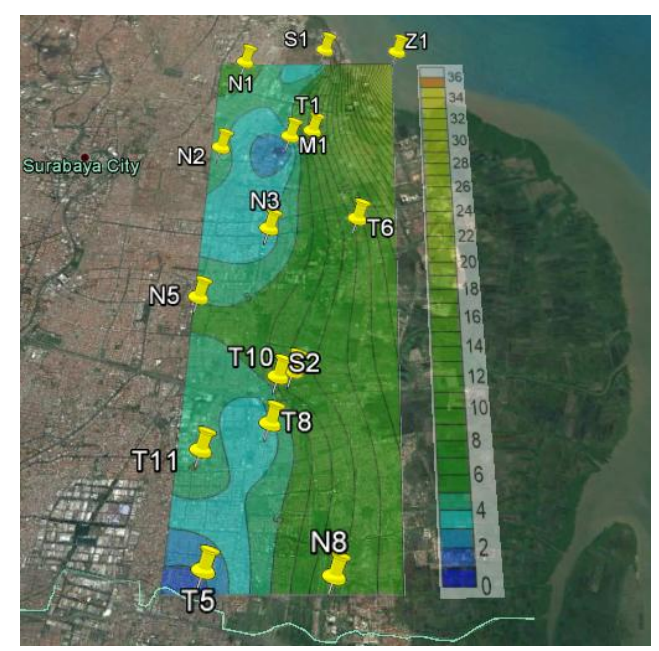

Gambar 12. Kontur TDS (dalam ppt).

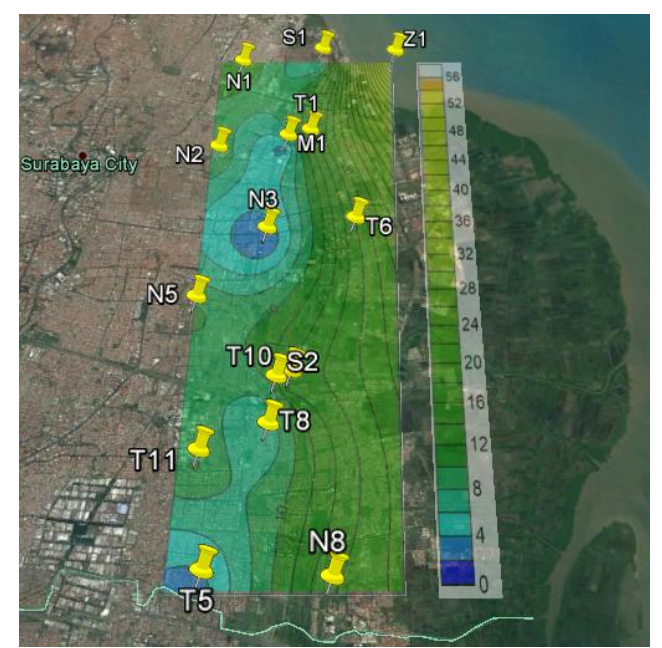

Gambar 13. Kontur Konduktivitas (dalam mS).

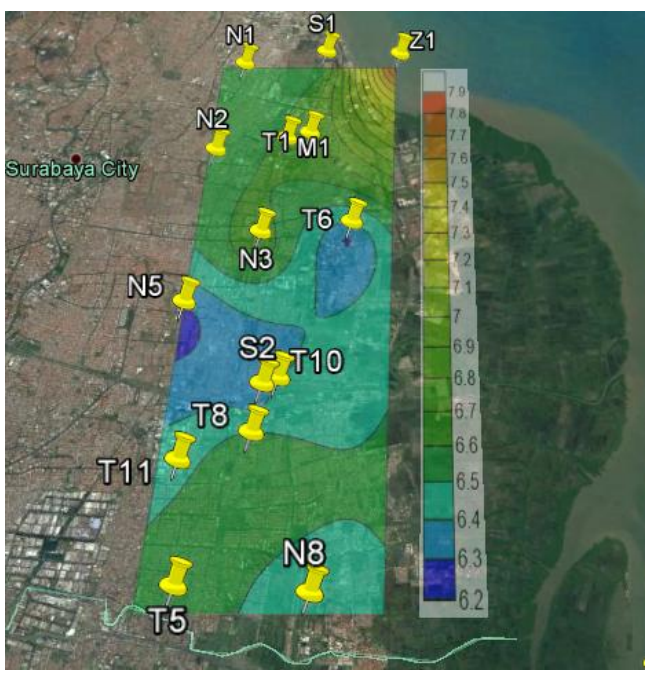

Gambar 14. Kontur pH.

Dari gambar kontur di atas terlihat adanya variasi kualitas air di Surabaya Timur. Pada kontur salinitas, TDS, dan konduktivitas menunjukkan hasil yang hampir sama. Jika dilihat, terdapat hubungan yang sistematik dengan jauhnya garis pantai. Semakin dekat dengan garis pantai, nilai kontur salinitas, TDS, dan konduktivitas akan semakin tinggi yang berarti bahwa semakin ke arah laut air menjadi semakin saline. Hal ini kemungkinan besar disebabkan karena adanya intrusi air laut.

Dari nilai salinitas air sumur dapat dibedakan menjadi beberapa kriteria. Menurut EPA SA Australia, air dapat dibagi menjadi lima jenis berdasarkan salinitasnya yaitu 0-1 ppt (fresh), 1-3 ppt (fresh to brackish), 3-5 ppt (brackish), 5-35 ppt (saline), dan 35 ppt keatas (hyper-saline). Dari pembagian tersebut maka kontur salinitas dapat dibagi menjadi lima kelompok besar seperti Gambar 12 di bawah.

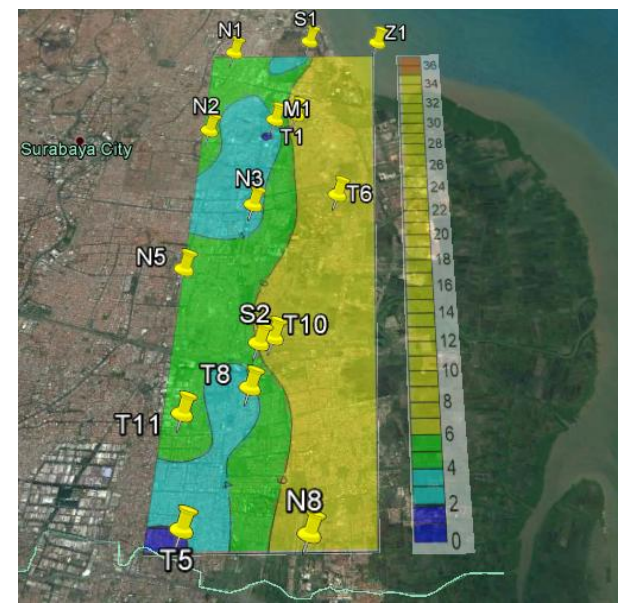

Gambar 15. Kontur Salinitas (Dikelompokkan).

Menurut EPA SA Australia, rasa air ketika diminum dapat dibagi menjadi lima menurut salinitasnya yaitu 0-0.08 (excellent), 0.08-0.5 (good), 0.5-0.8 (fair), 0.8-1 (poor), dan 1 keatas (unacceptable). Dari nilai salinitas air sumur dapat dilihat bahwa hanya sedikit air sumur di Surabaya Timur yang layak untuk diminum dikarenakan sebagian besar wilayah Surabaya Timur sudah didominasi oleh air asin. Air sumur yang masih layak untuk diminum terdapat di daerah kontur berwarna biru tua dan biru muda yaitu di daerah Manyar Kertoadi, Sutorejo bagian Barat, Penjaringan Timur, dan Rungkut Menanggal. 


\section{Analisa Pengukuran IP dan Resistivity \\ Daerah Sutorejo}

Pengukuran IP dan Resistivity di daerah Sutorejo (titik L) dilaksanakan pada tanggal 10 Oktober 2016 pada pukul 11.00 WIB sampai 22.00 WIB dengan cuaca mendung. Lokasi pengukuran merupakan tanah alluvial dengan sedikit vegetasi dengan jarak 3 meter terhadap pantai. Walaupun berjarak dekat dengan pantai, daerah ini masih terdapat air tawar dengan salinitas rendah yaitu 1.63 ppt. Sehingga air di daerah ini layak untuk diminum. Pengukuran geolistrik di daerah ini memotong 2 zona yaitu zona air tawar (fresh) dan zona air payau rendah (fresh to brackish). Bentangan pengukuran sebesar $80 \mathrm{~m}$ dengan jarak elektroda terkecil (a) sebesar 2.5 meter dan factor spasi (n) sebanyak 10. Sehingga didapatkan penampang dengan kedalaman 9 meter.

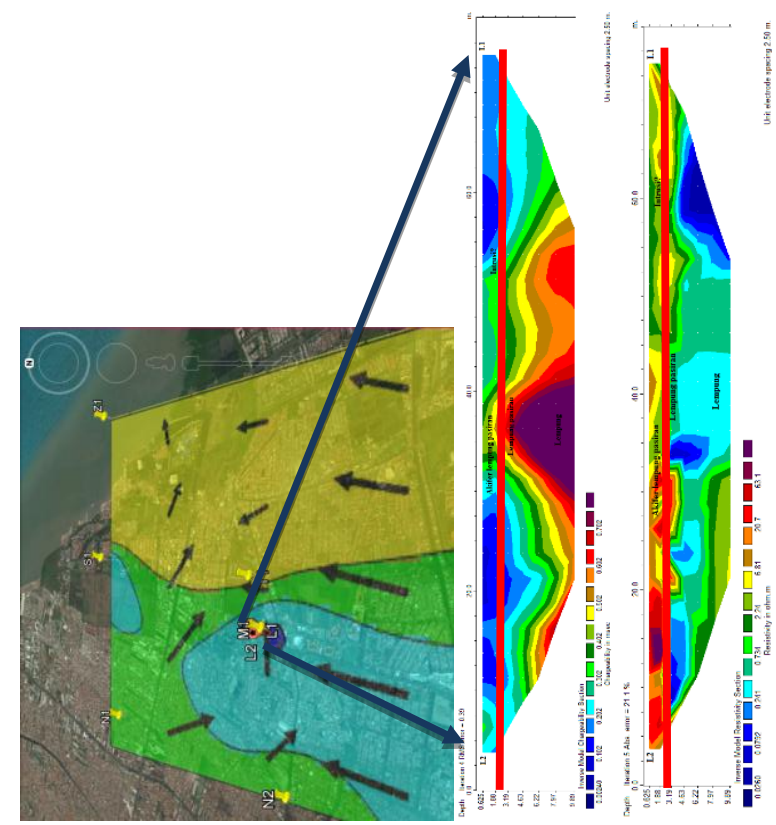

Gambar 16. Penampang IP (a) dan Resistivity

(b) Daerah Sutorejo.

Hasil penampang IP pada Gambar 16 menunjukkan nilai yang cukup bervariasi. Untuk mempermudah dalam menentukan perlapisan, digunakan data pengukuran resistivity pada Gambar 16 (b). Lapisan pertama memiliki nilai chargeabilitas yang rendah (0.00240-0.302 msec) yang ditunjukkan oleh warna biru. Apabila dibandingkan dengan data resistivitas maka terlihat dengan cukup jelas bahwa lapisan pertama memiliki kedalaman 0.6-3 meter dengan nilai resistivitas yang cukup tinggi (6.81-63.1 ohm.m). Lapisan pertama dapat diidentifikasi berupa lapisan akifer lempung pasiran (garis merah). Di bagian Tengah sampai Timur Laut (L1) didominasi oleh nilai resistivitas yang cukup rendah. Hal ini kemungkinan merupakan intrusi air laut dari arah Utara. Hal ini juga diperkuat oleh data chargeability yang memiliki nilai yang rendah (0.202 msec). Di bawah lapisan pertama merupakan lapisan lempung pasiran dengan kedalaman 3-8 meter (ketebalan 5 meter). Lapisan lempung pasiran ini memiliki nilai chargeabilitas yang cukup tinggi (0.302-0.702 msec). Sedangkan resistivitasnya memiliki nilai rendah (0.0260-0.734 ohm.m). Lapisan ketiga terletak pada kedalaman 8 meter memiliki nilai chargeabilitas tinggi $(0.702-1.30 \mathrm{msec})$ dan resistivitas sedang (0.734-6.81 ohm.m). Lapisan ketiga dapat diidentifikasi sebagai lapisan lempung.

Walaupun daerah pengukuran di Sutorejo ini berdekatan dengan pantai ( 3 meter), sumur disini (M1) memiliki kualitas air dengan salinitas yang kecil sebesar 1.63 ppt. Sehingga air di daerah ini masih layak untuk diminum. Daerah ini terlihat merupakan daerah batas intrusi. Bergeser sedikit ke arah Timur Laut, maka akan ditemukan air dengan salinitas payau dan asin. Kemungkinan besar daerah ini memiliki air yang masih bagus karena merupakan daerah zona tangkapan (discharge) dari daerah Barat Daya. Kontur muka air tanah terlihat cukup curam di daerah ini. Hal ini berarti bahwa aliran air cukup signifikan dari arah Barat Daya. Sehingga daerah ini tetap memiliki air yang baik. Apabila dibandingkan dengan nilai resistivity di kedalaman 0.6-3 meter yang merupakan zona akifer maka akan terlihat daerah Timur Laut memiliki resistivitas yang lebih kecil dibandingkan daerah Barat Daya. Kemungkinan resistivitas kecil (6.81 ohm.m) tersebut merupakan air laut. Sedangkan pada data IP sedikit menunjukkan adanya perbedaan chargeabilitas, di bagian Timur Laut terdapat nilai yang lebih lebih besar (0.202-0.302 msec) dibandingkan bagian Barat Daya yang didominasi oleh nilai chargeability kecil (0.00240 msec). 


\section{Daerah Klampis}

Pengukuran di daerah Klampis (titik G) dilaksanakan pada tanggal 11 Oktober 2016 dari pukul 10.00 WIB sampai 23.00 WIB dengan cuaca mendung berawan. Kondisi tanah merupakan tanah urukan dengan cukup banyak vegetasi. Lokasi daerah ini berjarak sekitar $6 \mathrm{~km}$ dari pantai dengan bentangan pengukuran sepanjang 100 meter. Air tanah di daerah ini merupakan air tanah payau rendah (fresh to brackish) dengan kadar 1-3 ppt. Bentangan geolistrik adalah sebesar $100 \mathrm{~m}$ dengan jarak elektroda terkecil (a) sebesar 2.5 meter dan factor spasi $(n)$ sebanyak 10 . Sehingga didapatkan penampang dengan kedalaman 9 meter.

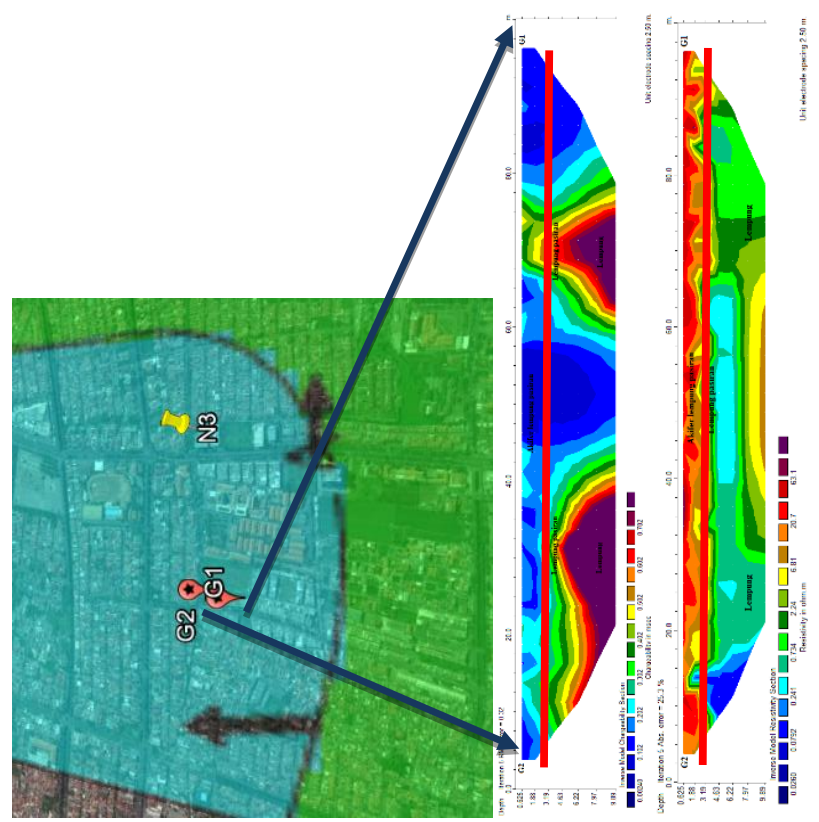

Gambar 17. Penampang IP (a) dan Resistivity 2D (b) Daerah Klampis.

Hasil pengolahan metode IP daerah Klampis dapat dilihat pada Gambar 17 (a). Hasil penampang pada daerah Klampis hampir sama dengan daerah Sutorejo. Dari penampang IP ini dapat dibagi menjadi tiga nilai range nilai. Nilai chargeabilitas rendah (0.00240-0.302 msec) ditandai dengan warna biru tua terletak di zona paling atas. Apabila dibandingkan dengan nilai resistivitas pada Gambar 17 (b) maka zona ini tepat berada di nilai resistivitas tinggi (6.81-63.1 ohm.m). Zona ini diinterpretasikan sebagai akifer pasiran dengan kedalaman 0.6-4 meter (garis merah). Akifer di daerah ini kemungkinan masih belum terkena dampak intrusi. Hal ini ditunjukkan oleh data chargeabilitas yang rendah (0.00240-0.302 $\mathrm{msec})$ dan data resistivitas yang memiliki nilai cukup tinggi (0.241-2.24 ohm.m). Selain itu, hal ini juga diperkuat oleh data sumur di dekat daerah pengukuran (sumur N3) yang memiliki kedalaman muka air tanah sebesar 0.74 meter dan nilai salinitas yang kecil yaitu 3.42 ppt. Di bawahnya terdapat beberapa bagian zona yang memiliki nilai chargeabilitas cukup rendah (0.302-0.602 $\mathrm{msec}$ ) ditandai dengan warna biru muda hingga hijau tua serta memiliki nilai resistivitas sedang (0.241-2.24 ohm.m). Lapisan ini merupakan lapisan lempung dengan sisipan pasir dengan kedalaman 4-8 m. Pada bentangan meter ke-30 dan 70 kedalaman 8 meter terdapat nilai chargeabilitas yang tinggi (0.602-1.82) dimana resistivity bernilai tidak terlalu kecil (2.24-6.81), perkiraan zona ini dapat berupa zona lempungan.

\section{Daerah ITS}

Pengukuran terakhir dilakukan di daerah dengan kualitas air berupa air asin. Daerah ini terletak di wilayah kampus ITS tepatnya berada di halaman BTH-BPPT. Lokasi pengukuran terletak 3 meter dari pantai. Pengukuran dilakukan pada tanggal 25 Nopember 2016 pada pukul 08.00-19.00 WIB. Kondisi tanah dipenuhi banyak vegetasi dan sedikit becek karena bekas hujan. Kondisi air di daerah ini merupakan air asin (saline) dengan kadar salinitas sebesar 8.52 ppt. Bentangan geolistrik adalah sebesar $100 \mathrm{~m}$ dengan jarak elektroda terkecil (a) sebesar 2.5 meter dan faktor spasi ( $n$ ) sebanyak 10. Penetrasi kedalaman yang didapatkan sebesar 9 meter.

Hasil penampang IP daerah ITS dapat dilihat pada Gambar 18 (1). Hasil penampang IP pada daerah ITS menunjukkan hasil chargeabilitas yang relatif rendah. Untuk memudahkan interpretasi dilakukan perbandingan dengan data resistivity yang ditunjukkan pada Gambar 18 (B). Terlihat bahwa penampang resistivity menunjukkan hasil yang cukup baik untuk menjelaskan adanya suatu perlapisan akuifer. Dari penampang resistivity dapat dibagi menjadi 3 sistem perlapisan utama. 
Lapisan pertama dengan kedalaman 0-2.5 meter merupakan lapisan akifer pasiran (garis merah). Lapisan ini memiliki nilai resistivitas yang cukup besar (6.81-63.1 ohm.m) dan nilai chargeabilitas cukup rendah (0.202-0.302 msec).

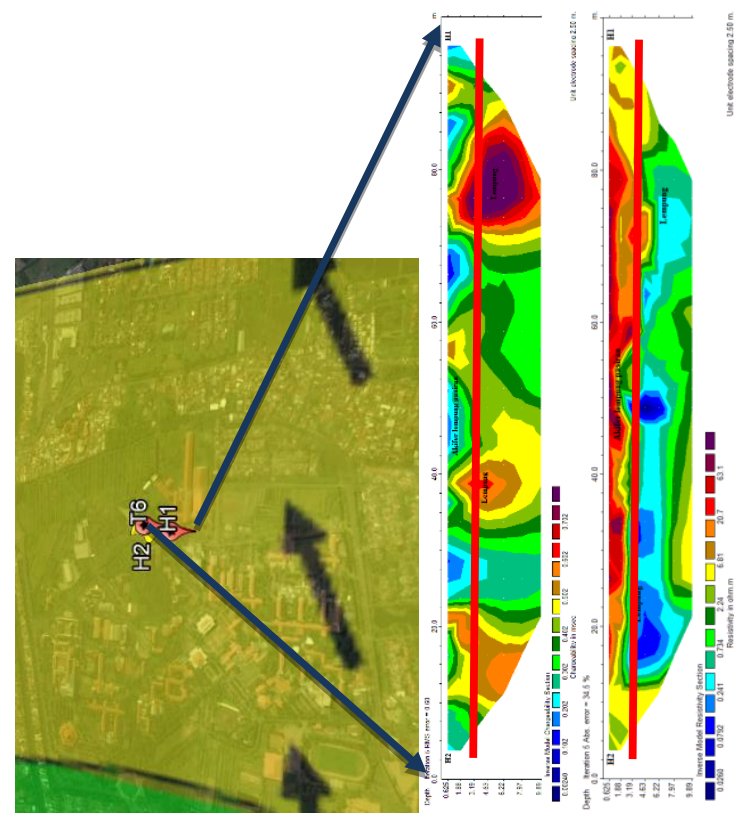

Gambar 18. Penampang IP (a) dan Resistivity 2D (b) daerah ITS.

Akifer daerah ini merupakan akifer air asin. Hal ini sesuai dengan data sumur T6 yang terletak di dekat lokasi pengukuran. Hasil resistivitas kurang dapat menunjukkan adanya intrusi air laut sedangkan hasil chargeabilitas memiliki nilai yang cukup rendah (0.202 msec) yang bisa berarti bahwa nilai tersebut merupakan nilai chargeabilitas air asin. Bisa berarti, nilai resistivitas yang menunjukkan nilai tidak terlalu kecil pada akifer air asin disebabkan karena akifer terdapat pada zona pasiran yang berasosiasi lempungan (clay). Lapisan kedua merupakan lapisan lempung pasiran dengan kedalaman 2.5-7.5 meter. Lapisan ini memiliki nilai resistivitas yang relatif kecil (0.0260-0.734 ohm.m) dan chargeabilitas kecil (0.502-0.602 msec). Lapisan ketiga dengan kedalaman 8 meter merupakan lapisan lempung. Lapisan ini memiliki nilai resistivitas sedang $(0.734-6.81$ ohm.m) dan chargeabilitas sedang $(0.602-0.782 \mathrm{msec})$.

\section{PENUTUP}

Kesimpulan

Kesimpulan yang didapat dari penelitian ini antara lain.

1. Metode IP memiliki hasil yang cukup baik untuk mengidentifikasi polarizing material, misalnya lempung (2.24-6. $81 \mathrm{msec})$.

2. Metode resistivity dapat mengidentifikasi zona akifer dengan baik beserta memperkirankan tipe akifernya. Akifer dengan nilai resistivitas rendah (0.026 ohm.m) besar kemungkinan merupakan air asin.

\section{Saran}

Saran yang dapat diberikan berdasarkan hasil dan kesimpulan untuk membangun hipotesahipotesa selanjutnya antara lain.

1. Metode IP 2D dalam mengidentifikasi zona akifer dan intrusi air laut memerlukan adanya korelasi dengan data geofisika lainnya. Misalnya dalam penelitian ini, metode IP 2D kurang dapat memprediksi adanya suatu perlapisan akifer dengan baik. Di sisi lain, metode resistivity 2D dapat dengan baik menunjukkan adanya perlapisan akifer. Tentunya hal ini akan memudahkan untuk melakukan interpretasi

\section{Ucapan Terima Kasih}

Penulis mengucapkan terima kasih kepada para dosen pembimbing Bapak Dwa Desa Warnana dan Bapak Amien Widodo atas ide penulisan dan pengarahannya selama proses penelitian hingga penulisan

\section{DAFTAR PUSTAKA}

Ambarsari, E. S., 2013. Aplikasi Metode Geolistrik untuk Identifikasi Intrusi Air Laut Studi Kasus Semarang Utara. Jurusan Fisika FMIPA UNS.

Bahri, S., \& Madlazim., 2012. Pemetaan Topografi, Geofisika, dan Geologi Kota Surabaya. Jurnal Penelitian Fisika dan Aplikasinya. 
Balia, R., \& Viezzoli, A., 2015. Integrated Interpretation of IP and TEM data for Salinity Monitoring of Aquifers and soil in the coastal area of Muravera (Sardinia, Italy). Bollettino di Geofisica Teorica ed Applicata.

BAPPEDA., 2013. Kota Surabaya. Surabaya: BAPPEDA.

Bery, A. A., Saad, R., Mohamad, E. T., Jinmin, M., Azwin, I., Tan, N. M., \& Nordiana, M. M., 2012. Electrical Resistivity and Induced Polarization Data Correlation with Conductivity for Iron Ore Exploration. EJGE.

Eddy, H., 2010. Pemodelan Data IP-Resistivity dan Magnetik untuk Melokalisir Endapan Nikel Laterit di Daerah "LTD", Sulawesi Tenggara. Program Studi Fisika FMIPA UI.

Enviromental Info., 2015, 4 Mei. Diambil kembali dari EPA SA Australia: http://www.epa.sa.gov.au/environmental_info/wate r_quality/threats/salinity

Hakim, A., 2015, 26 Oktober. Menggali "Mutiara" di Pesisir Kenjeran Surabaya. Diambil kembali dari Antara Jatim: http://www.antarajatim.com

Hendrayana, H., 2002. Intrusi Air Asin ke dalam Akuifer di Daratan. Geological Engineering Dept., hh. 1-15.

ITS, P.-K., \& BAPEDDA., 1999. Studi Sistem Jaringan Resapan Air Buatan di Kecamatan Kenjeran Kotamadya DATI II Surabaya. Surabaya: Laporan Penelitian .

Martinho, E., Almeida, F., \& Matias, M. J., 2004. TimeDomain Induced Polarization in the Determination of the Salt/Freshwater Interface (Aveiro - Portugal). SWIM.

N, M. I., Achmad, R. T., \& Widodo, S., 2006. Pemetaan Sebaran Air Tanah Asin Pada Aquifer Dalam di Wilayah Semarang Bawah. Berkala Fisika.

Priambodo, I. C., Purnomo, H., Rukmana, N., \& Juanda., 2011. Aplikasi Metoda Geolistrik Konfigurasi WennerSchlumberger pada Survey Gerakan Tanah di bajawa, NTT. Pusat Vulkanologi dan Mitigasi Bencana Geologi, hh. 1-10.

Profil Keanekaragaman Hayato Kota Surabaya. 2012. Surabaya: Badan Lingkungan Hidup Pemerintah Kota Surabaya.

Rahmah, S., 2009. Pencitraan Dua Dimensi Data Resistivity dan Induced Polarization untuk Mendelineasi Deposit Emas Sistem Epithermal di Daerah " $X$ ". Departemen Flsika FMIPA UI.

Setiyono, A., Wahyudi, \& Suntoyo., 2013. Studi Potensi Air Tanah di Pesisir Surabaya Timur untuk Budidaya Perikanan Air Payau. Jurnal Teknik POMITS.

Sharma, P. V., 1997. Enviromental and Engineering Geophysics. Cambridge: Cambridge University Press.
Suharto, B., Pranama, A., Firman, M., \& Sumarno. Investigasi Penyebaran Intrusi Air Laut di Kota Bengkulu dengan Metode Geolistrik Tahanan Jenis Studi Kasus : Daerah Kampung Cina, Sumur Melele dan Berkas. Jurusan Fisika FMIPA Universitas Bengkulu.

Surabaya, P. K., 2013. Buku Laporan Status Lingkungan Hidup Daerah Kota Surabaya. Surabaya: Pemerintah Kota Surabaya Provinsi Jawa Timur.

Telford, W. M., 1990. Applied Geophysics Second Edition. Melbourne: Cambridge University Press.

UNdata., 2010. UNSD Demographic Statistics. Diambil kembali dari UNdata: http://data.un.org

Wibowo, M., 2001. Potensi Sumber Daya Air Tanah di Surabaya Berdasarkan Survei Geolistrik Tahanan Jenis. Jurnal Teknologi Lingkungan. 